\title{
RGxE: An R Program for Genotype $x$ Environment Interaction Analysis
}

\author{
Mahendra Dia1, Todd C. Wehner ${ }^{1}$, Consuelo Arellano ${ }^{2}$ \\ ${ }^{1}$ Department of Horticultural Science, North Carolina State University, Raleigh, USA \\ ${ }^{2}$ Statistics Department, North Carolina State University, Raleigh, USA \\ Email: *tcwehner@gmail.com
}

How to cite this paper: Dia, M., Wehner, T.C. and Arellano, C. (2017) RGxE: An R Program for Genotype $\mathrm{x}$ Environment Interaction Analysis. American Journal of Plant Sciences, 8, 1672-1698. https://doi.org/10.4236/ajps.2017.87116

Received: March 31, 2017

Accepted: June 20, 2017

Published: June 26, 2017

Copyright ( 92017 by authors and Scientific Research Publishing Inc. This work is licensed under the Creative Commons Attribution International License (CC BY 4.0).

http://creativecommons.org/licenses/by/4.0/

cc) (i) Open Access

\begin{abstract}
Genotype $\mathrm{x}$ environmental interaction $(\mathrm{GxE})$ can lead to differences in performance of genotypes over environments. GxE analysis can be used to analyze the stability of genotypes and the value of test locations. We developed an Rlanguage program ( $\mathrm{RGXE}$ ) that computes univariate stability statistics, descriptive statistics, pooled ANOVA, genotype $F$ ratio across location and environment, cluster analysis for location, and location correlation with average location performance. Univariate stability statistics calculated are regression slope $\left(b_{i}\right)$, deviation from regression $\left(S_{d}^{2}\right)$, Shukla's variance $\left(\sigma_{i}^{2}\right)$, S square Wricke's ecovalence $\left(W_{i}\right)$, and Kang's yield stability $\left(Y S_{i}\right)$. RGxE is free and intended for use by scientists studying performance of polygenic or quantitative traits over multiple environments. In the present paper we provide the RGxE program and its components along with an example input data and outputs. Additionally, the RGxE program along with associated files is also available on GitHub at https://github.com/mahendra1/RGxE, http://cucurbitbreeding.com/todd-wehner/publications/software-sas-r-project/ and http://cuke.hort.ncsu.edu/cucurbit/wehner/software.html.
\end{abstract}

\section{Keywords}

Genotype x Environment Interaction, R Programming Language,

RGxE, Univariate, Multivariate

\section{Introduction}

Genotype $\mathrm{x}$ environmental interaction $(\mathrm{GxE})$ refers to the modification of genetic factors by environmental factors, and to the role of genetic factors in determining the performance of genotypes in different environments. GxE can occur for quantitative traits of economic importance and is often studied in plant and animal breeding, genetic epidemiology, pharmacogenomics and con- 
servational biology research. The traits include reproductive fitness, longevity, height, weight, yield, and disease resistance.

Selection of superior genotypes in target environments is an important objective of plant breeding programs. A target environment is a production environment used by growers [1] [2] [3] [4] [5]. In order to identify superior genotypes across multiple environments, plant breeders conduct trials across locations and years, especially during the final stages of cultivar development. GxE is said to exist when genotype performance differs over environments. Performance of genotype can vary greatly across environment because of the effect of environment on trait expression. Cultivars with high and stable performance are difficult to identify, but are of great value [6] [7].

Since it is impossible to test genotypes in all target environments, plant breeders do indirect selection using their own multiple-environment trials, or test environments. GxE reduces the predictability of the performance of genotypes in target environments based on genotype performance in test environments [8]. An important factor in plant breeding is the selection of suitable test locations, since it accounts for $\mathrm{GxE}$ and maximizes gain from selection [9]. An efficient test location is discriminating, and is representative of the target environments for the cultivars to be released. Discriminating locations can detect differences among genotypes with few replications. Representative locations make it likely that genotypes selected will perform well in target environments [9].

The analysis of variance (ANOVA) is useful in determining the existence, size and significance of $\mathrm{GxE}$. In order to determine $\mathrm{GxE}$ for a group of elite cultivars, genotypes are often considered to be fixed effects and environments random. However, for the purpose of estimating breeding values using best linear unbiased prediction (BLUP), genotypes are considered to be random and environments fixed. Some statisticians consider genotypes random effect, provided that the objective is to select the best ones [10]. If GxE is significant, additional stability statistics can be calculated.

Several statistical methods have been proposed for stability analysis. These methods are based on univariate and multivariate models. The present paper focuses on univariate models for the analysis of stability measured using R programming, so a brief description of each stability measure is provided below.

The most widely used methods are univariate stability models based on regression and variance estimates. According to the regression model, stability is expressed in terms of the trait mean $(M)$, the slope of regression line $\left(b_{i}\right)$ and the sum of squares for deviation from regression $\left(S_{d}^{2}\right)$. High mean of a genotype performance is a precondition of stability. The slope $\left(b_{i}\right)$ of regression indicates the response of genotype to the environmental index, which is derived from the average performance of all genotypes in each environment. If $b_{i}$ is not significantly different from unity, the genotype is adapted in all environments. A $b_{i}$ greater than unity describes genotypes with higher sensitivity to environmental change (below average stability), and greater specificity of adaptability to high 
yielding environments. A $b_{i}$ less than unity provides a measure of greater resistance to environmental change (above average stability), and therefore increasing specificity of adaptability to low yielding environments.

The variance parameters that measure stability statistics include stability ecovalence $\left(W_{i}^{2}\right)$ proposed by [11], stability variance $\left(\sigma_{i}^{2}\right)$ proposed by [12], and yield stability $\left(Y S_{i}\right)$ proposed by [13].

Ecovalence stability index $\left(W_{i}^{2}\right)$ of a genotype is its contribution to the GxE squared and summed across all environments. Since the value of $W_{i}^{2}$ is expressed as a sum of squares, a test of significance for $W_{i}^{2}$ is not available. [12] proposed an unbiased estimate $\left(\sigma_{i}^{2}\right)$ of the variance of GxE plus an error term associated with genotype. Shukla's stability variance $\left(\sigma_{i}^{2}\right)$ is a linear combination of Wricke's ecovalence $\left(W_{i}^{2}\right)$. Shukla's stability statistic measures the contribution of a genotype to the $\mathrm{GxE}$ and error term, therefore a genotype with low $\sigma_{i}^{2}$ is regarded as stable. According to [13], $W_{i}^{2}$ and $\sigma_{i}^{2}$ are equivalent in ranking genotypes for stability.

The [14] stability statistic $\left(Y S_{i}\right)$ is a nonparametric stability procedure in which both the mean $(M)$ and [12] stability variance $\left(\sigma_{i}^{2}\right)$ for a trait are used as selection criteria. This method gives equal weight to $M$ and $\sigma_{i}^{2}$. According to this method, genotypes with $Y S_{i}$ greater than the mean $Y S_{i}$ are considered stable [14] [15] [16].

Genotype $F$ ratio for each test location and correlation of test location with average location are important measures of location value. When the mean of all genotypes are equal, then the $F$ ratio will be close to 1 . If analysis of variance is run by location, then high genotype $F$ ratio indicates high discriminating ability for that location. High and significant value of Pearson correlation of each location with the mean of all locations indicates strong representation of mean location performance.

Our objective was to develop an Rlanguage program (RGxE) that gives an output for genotype stability and location value using univariate models, descriptive statistics, genotype $F$ ratio across location and environment, cluster analysis for location, and location correlation with average location performance. In addition to the RGxE program, [17] provided a SAS program (SASGxE) that computes multivariate stability statistics using $\mathrm{R}$ program along with univariate stability statistics and location value using SAS programming. These multivariate stability statistics include the additive main effects and multiplicative interaction (AMMI) model, and genotype main effects plus GxE (GGE) model. RGxE uses R software (version 3.1.3 and higher). RGxE is freely available, annotated, and intended for scientists studying performance of polygenic or quantitative traits under different environmental conditions. In the present paper we provide the general features of RGxE program and along with the functionality of each module and their outputs. A supplemental file is provided with the RGxE program, instructions for the user-enetered fields required in RGxE program, interpretation of univariate stability statistics, example input data, and output from example input data. The RGxE program along with asso- 
ciated files is also available on GitHub at https://github.com/mahendra1/RGxE, http://cucurbitbreeding.com/todd-wehner/publications/software-sas-r-project/ and http://cuke.hort.ncsu.edu/cucurbit/wehner/software.html.

\section{General Features and Functionality of the RGxE Program}

\subsection{Overview of the RGxE Program}

$\mathrm{RGxE}$ is a user friendly and annotated $\mathrm{R}$ program that will allow user to analyze genotype stability and evaluate test location value of balanced mult-location replicated trial data. This program generates output (.csv or .txt) into the same folder from where it reads input dataset and Console window of helper application "R studio" [18] of R statistical software [19]. A schematic representation of $\mathrm{RGxE}$ is presented in Figure 1. Below are the key components of RGxE program which user can independently run.

\subsection{Installing and Loading Packages}

RGxEuses dplyr [20], tidyr [21], broom [22], agricolae [23], lme4 [24], afex [25], cluster [26], and grDevices [19] packages. The dplyr, tidyr, broom, agri-

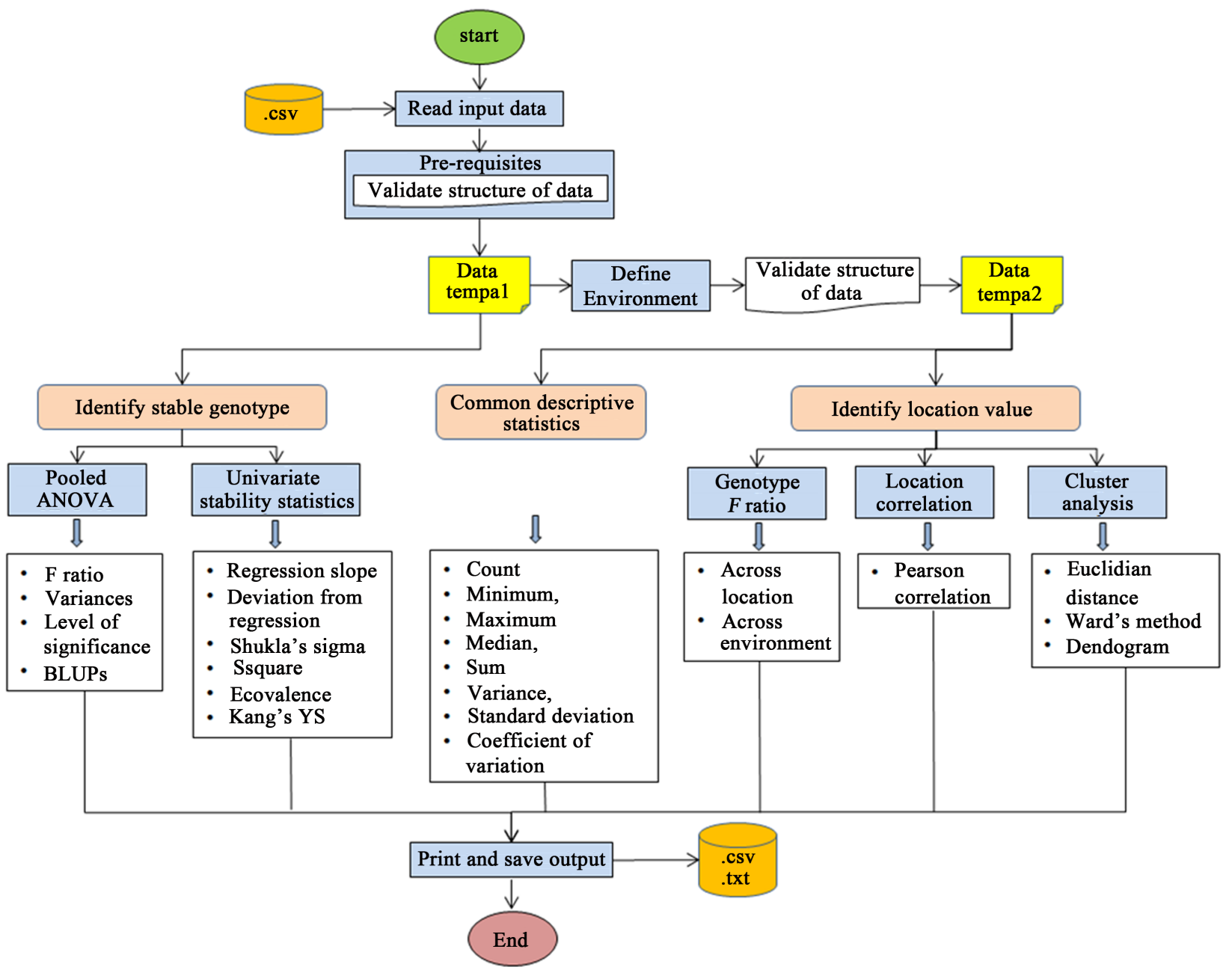

Figure 1. Overview of overall process of RGxE program for genotype stability and location value. 
colae, lme4, afex, cluster, and grDevices packages are available from the Comprehensive R Archive Network (CRAN), therefore they can be installed as any other packages, by simply typing:

$$
\begin{aligned}
& \text { i nst al I . packages( "dpl yr") } \\
& \text { i nst al I . packages( "t i dyr") } \\
& \text { i nst al I . packages( "br oom") } \\
& \text { i nst al I . packages( "agr i col ae") } \\
& \text { i nst al I . packages( "I me4") } \\
& \text { i nst al I. packages( "af ex") } \\
& \text { i nst al I. packages( "cl uster ") } \\
& \text { i nst al I. packages( "gr Devi ces") }
\end{aligned}
$$

Once installed, the packages have to be loaded before they can be used. This can be done through the I i brary() or requi re( ) command, as shown below.
I i brary(ti dyr)
I i brary( dpl yr )
I i brary( sql df )
I i brary( I me4)
I i brary( af ex)
l i brary( broom)
I i brary( agri col ae)
I i brary( cl ust er )
I i brary( gr Devi ces)

\subsection{Input Data and Validation}

RGxE starts with user-entered field to read input data. Instructions on user enetered fields are presented in Supplemental Material. The user is required to set current working directory using set wd( ), which is input data file location, and pass input data file name. RGxE requires an input data file in .csv (comma separated value) format. Highlighted fields are user entered in the code shown below for Windows and iOS (Mac) operating system, respectively.

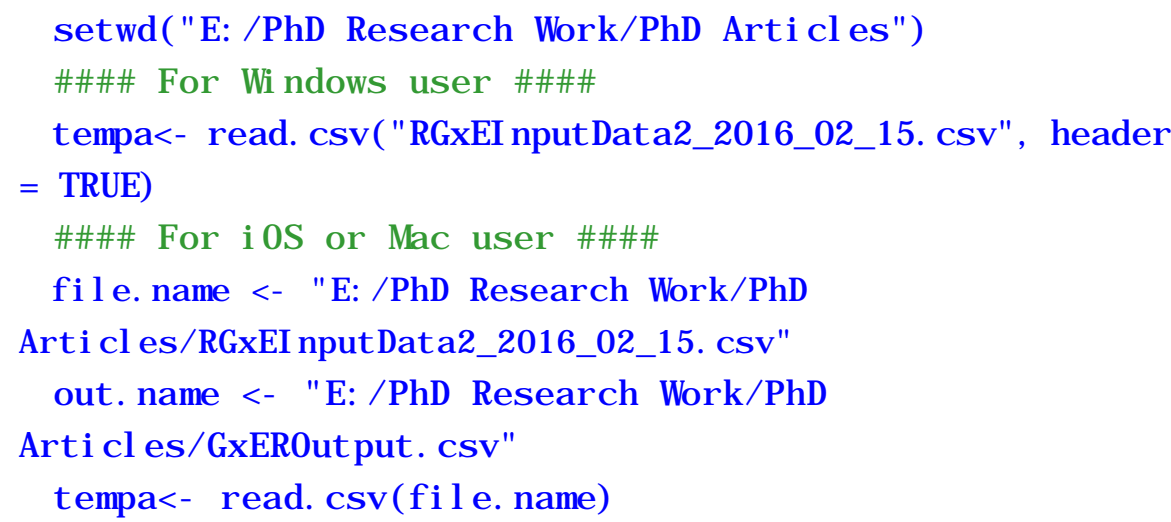

The input data file is comprised of column names including YR (year), LC (location), RP (replication), CLT (cultigen or genotype), and dependent variable (Trait). Sample input data is presented in Supplemental Material. User is re- 
quired not to change the column names as program takes same variable name for the analysis. Dependent variable in example input data is yield $\left(\mathrm{Mg}^{\circ} \mathrm{ha}^{-1}\right)$ of watermelon. Hereafter, a word "genotype" is used to indicate cultigen, cultivar, variety or genotype. RGxE validates the structure of input data, with below arguments, so that correct column types (numeric, logical, factor, or character) are used for statistical analysis.

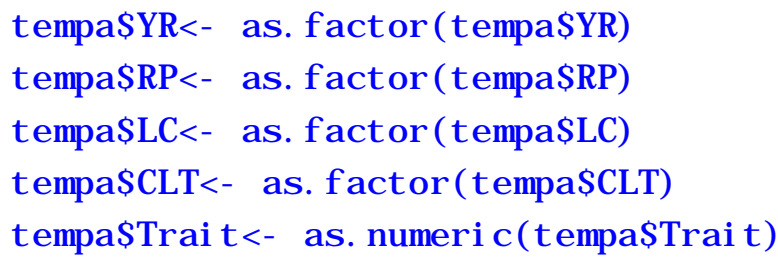

\$CLT : Factor w/ 10 I evel s "Cal houngray", ..: 3192 $5471068 \ldots$

\$ Trait: num 56. 2 74. $232.674 .264 .8 \ldots$

Top 6 rows of example input data can be viewed using head( ) command. head( t empa)

\section{YR LC RP}

12009 KN 1Earl yCanada 56. 236

$22009 \mathrm{KN}$ 1Cal hounGray 74. 167

$\begin{array}{lllll}3 & 2009 \mathrm{KN} 1 & \text { StarbriteF1 32. } 601\end{array}$

42009 KN 1Cri msonSweet 74. 167

52009 KN 1Geor gi aRattl esnake 64. 794

$62009 \mathrm{KN} 1 \quad$ Fi estaF1 70.907

\subsection{Genotype Stability Statistics}

\subsubsection{Analysis of Variance (ANOVA)}

In multi-location replicated trial data, combined ANOVA is performed with the objectives to identify the significance of different effects; estimate and compare mean for levels of fixed factors; and estimate the size of genotype and GxE variance components. The ANOVA model comprises four factors: genotype (CLT), location (LC), year (YR), and replication or block (RP) nested within locations and year. The response of the genotype $i$ in the location $j$, year $k$ and replication $r$ is presented as:

$$
\begin{aligned}
\text { Response }= & m+C L T_{i}+L C_{j}+Y C_{k}+R P_{r}\left(L C_{j} * Y R_{k}\right)+C L T_{i} * L C_{j} \\
& +C L T_{i} * Y R_{k}+L C_{j} * Y R_{k}+C L T_{i} * L C_{j} * Y R_{k}+\text { Error }_{i j k r}
\end{aligned}
$$


where $m=$ grand mean. Depending on the objectives of the analysis, the genotype, location and year are defined as random or fixed effect, which gives five different ANOVA models (Table 1). The genotype is random when the aim is to estimate variance components, genetic parameters, genetic gains expected from selection or different breeding strategies etc. Conversely, genotype is fixed factor when aim is to make comparison of test material for selection or recommendation. Similarly, location is considered as random when the main interest is to estimate variance components for sites that are representative of the relevant population within target region. Location is fixed when interest is to make explicit comparison of one level another and each location represents a well-defined area with relative to crop management. The year and replication are usually treated as random factor.

Different combinations of random and fixed effects in ANOVA model have implications for the expectations of mean square (MS) values with the possible modification of the error term to be adopted in the $F$ test. Therefore, sometimes the $F$ test is not as straightforward as the ratio between two mean squares.

RGxE computes five different cases of ANOVA:

- case 1: CLT, YR, LC and RP-all random

- case 2:CLT, YR and LC - fixed; RP-random

- case 3:CLT-fixed; LC, YR and RP-random

- case 4: LC-fixed; CLT, YR and RP-random

- case 5: CLT and LC-fixed; YR and RP-random

For random effect $\mathrm{RGxE}$ computes estimates of variance components using I mer ( ) function of lme4 package. The significance of random effects is computed using likelihood ratio test to attain p-values. Likelihood is the probability of the data given a model. The logic of the likelihood ratio test is to compare the likelihood of two models with each other. The model without the factor that you are interested in (null model) is compared with model with the factor that you are interested in (full model) using anova( ) function. It gives a Chi-Square

Table 1. ANOVA models including the factors genotype (CLT), location (LC), year (YR), and replication (RP) for multi-location replicated trials across years in a randomized complete block design.

\begin{tabular}{|c|c|c|c|c|c|c|}
\hline \multirow{2}{*}{ Source of variation } & \multirow{2}{*}{ DF } & \multicolumn{5}{|c|}{ Fixed vs. random effects } \\
\hline & & Case 1 & Case 2 & Case 3 & Case 4 & Case 5 \\
\hline CLT & $g-1$ & Random & Fixed & Fixed & Random & Fixed \\
\hline LC & $1-1$ & Random & Fixed & Random & Fixed & Fixed \\
\hline YR & $y-1$ & Random & Fixed & Random & Random & Random \\
\hline $\mathrm{RP}\left(\mathrm{LC}^{\star} \mathrm{YR}\right)$ & $(r-1) l y$ & Random & Random & Random & Random & Random \\
\hline $\mathrm{CLT}^{\star} \mathrm{LC}$ & $(g-1)(1-1)$ & Random & Fixed & Random & Random & Fixed \\
\hline $\mathrm{CLT}^{\star} \mathrm{YR}$ & $(g-1)(y-1)$ & Random & Fixed & Random & Random & Random \\
\hline $\mathrm{LC}^{\star} \mathrm{YR}$ & $(1-1)(y-1)$ & Random & Fixed & Random & Random & Random \\
\hline $\mathrm{CLT}^{\star} \mathrm{LC}^{\star} \mathrm{YR}$ & $(g-1)(1-1)(y-1)$ & Random & Fixed & Random & Random & Random \\
\hline Pooled error & $(r-1)(g-1) l y$ & & & & & \\
\hline
\end{tabular}


value, the associated degrees of freedom and p-value. According to Wilk's theorem, the negative two times the log likelihood ratio of two models approaches a Chi-Square distribution with $\mathrm{k}$ degrees of freedom, where $\mathrm{k}$ is number of random effects tested. RGxE create user defined anova_I rt ( ) function to compute likelihood ratio test and it is stored in ANOVA model Case I code.

The type III sum of squares (SS), MS, Fvalue of fixed effects are computed by fitting model in anova( ) function of lme4 package. The significance (p-value) of fixed effects is computed using m $\mathrm{xed}()$ function of afex package. The mi $x e d()$ function computes type III like p-values using default method via Kenward-Roger approximation for degrees of freedom.

To identify each experimental unit (EU) uniquely a distinct value must be assigned to EU. RGxE assign a distinct value to each combination of replication (RP) nested within location (LC) $\mathrm{x}$ year (YR) and use this new term (RPi d) in model. After installing and calling packages, user can independently compute five different ANOVA models while feeding input data ( $\mathrm{t}$ empa) in below code. User friendly output is generated in "dat a. $\mathrm{fr}$ are" class using dplyr and tidyr packages.

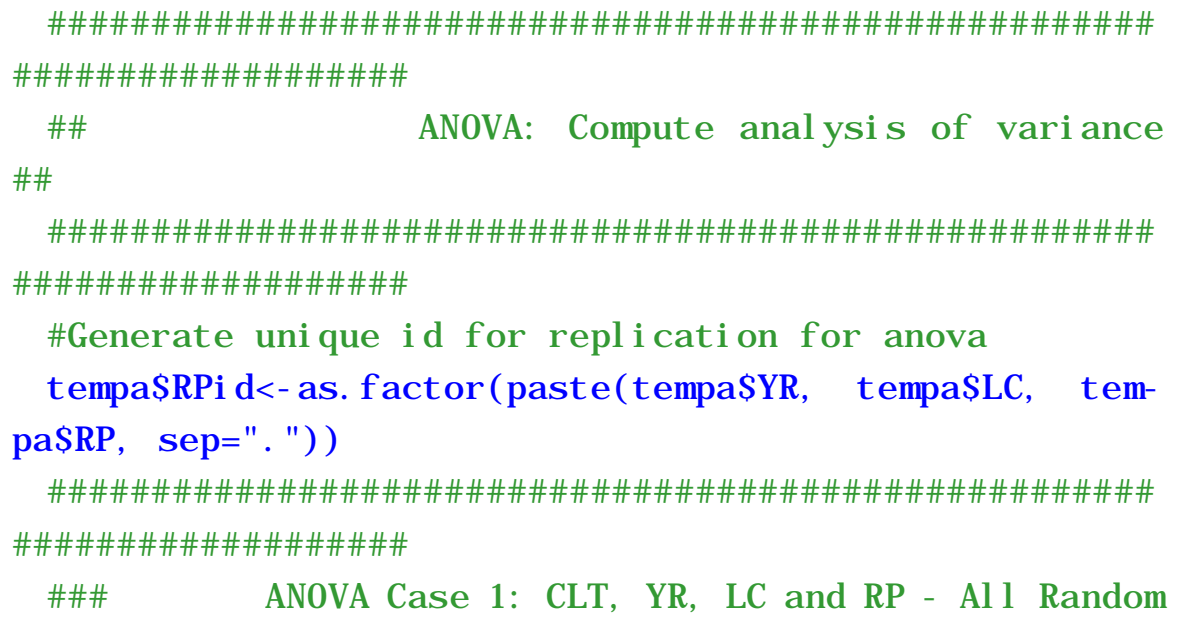

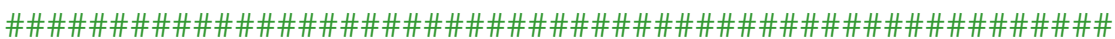

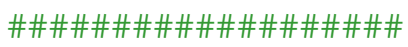

\#Gener ate uni que i d for repl i cat i on for anova

t empa \$RPi $d<-$ as. f act or ( past e( t empa\$YR, t empa\$LC, t em pa\$RP, sep="."))

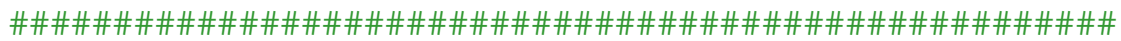

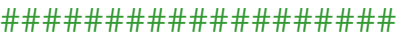

\#\#\# ANOVA Case 1: CLT, YR, LC and RP - Al I Random \#\#\#

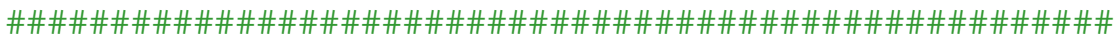

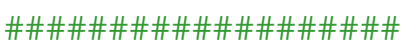

\# ul I nodel

fit.f $1<\mid \operatorname{mer}(\operatorname{Tr}$ ai $t \sim 1+(1 \mid \mathrm{YR})+(1 \mid \mathrm{LC})+(1 \mid \mathrm{CLT})+$ ( 1 YR: LC) +

$$
\begin{aligned}
& (1 \mid \text { YR: } C L T)+(1 \mid L C: C L T)+(1 \mid \text { YR: LC: } C L T)+ \\
& (1 \mid R P i d), \text { dat a=tempa) }
\end{aligned}
$$

\#nrodel summary

summary $1<\operatorname{summary}($ f i t. f 1$)$

\#vari ance of random factors

vari ance $<$ as. dat a. frame( summary $1 \$$ var cor)

\#dr op r ownames

rownames (vari ance) $<$ NULL

vari ancel < vari ance \%\% sel ect (-var 1, - var 2 ) \% \% 
rename ( sov $=g r p$, Var i ance $=v \operatorname{cov}, \quad$ st ddev $=$ sdcor $)$

\#Type 3 test of hypothesis

\#Type III Wal d chi square tests

anova(fit.f 1, type="III")

\#Type 1 test of hypothesis

anova( fit.f 1, type=" margi nal ", test $=" F "$ )

\#nodel fitness

anovacase $1<$ pl ot $(\mathrm{fit} . \mathrm{f} 1$,

mai $n="$ Mbdel fitness Case 1: CLT, YR, LC and RP - Al I

Random", $\quad x \mid a b=$ "Predi cat ed Val ue", $y l a b=$ "Resi dual ")

\#LRT - I i kel i hood rat i o test for computing si gni fi cance of $r$ andom ef $f$ ect

\#create functi on (anova_I rt) for Li kel i hood rati o test, where parameters

$\#$ \#=out put dat as et name; exampl e- anovalr

\#b ful I model name; example-fit.f 1

\# $=$ reduced nodel name; exampl e-fit.f Ir

\#d=ef f ect name; exampl e- "RPi d", NOTE: call it i $n$ quot at i on

anova_I rt $<$ function $(a, b, c, d)\{$

\# evel of signi i cance

$a<\operatorname{anova}(b, c)$

\#convert anova into data frame

$a<$ data.frame $(a)$

\#convert rownames i nto col um

a\$name $<$ rownames $(a)$

\# dropr ownarres

rownames $(a)<$ NULL

$a<a \%$ \%ilter(name =" b") $\% \%$

mit at $e($ sov $=d) \quad \% \%$ sel ect ( sov, Pr_Chi sq =

starts_wi th( "Pr... Chi sq. " ) )

\# return the resul t

ret urn(a)

\}

\#nul I model for YR

fi t. $f 1 y<\mid \operatorname{mer}(\operatorname{Tr}$ ai $t \sim 1+(1 \mid L C)+(1 \mid C L T)+(1 \mid Y R: L C)+$ ( $1 \mid$ YR: CLT) +

$$
(1 \mid \text { LC: CLT) + ( 1| YR: LC: CLT) + (1| RPi d), }
$$

dat $a=$ t empa)

\# evel of si gni fi cance

\#call function anova_Irt

anovaly < anova_I rt ( anovaly, fi t.f 1, fit.f 1y, "YR")

\#nul I model for LC

fit.f $1|<| \operatorname{mer}(\operatorname{Tr}$ ai $t \sim 1+(1 \mid$ YR $)+(1 \mid$ CLT) + (1|YR: LC) + 
( 1|YR: CLT) +

dat $a=t$ empa)

$(1 \mid \mathrm{LC}: \mathrm{CLT})$ + ( 1| YR: LC: CLT) + ( 1| RPi d) ,

\# evel of significance

\#cal I function anova_Irt

anova1l $<$ anova_Irt(anovall, fit.f $1, \mathrm{fit} . \mathrm{f} 1 \mathrm{ll}$, "LC")

\#nul I model for CLT

fit.f 1c $<1 \operatorname{mer}(\operatorname{Tr}$ ai $t \sim 1+(1 \mid Y R)+(1 \mid L C)+(1 \mid$ YR: LC $)+$ ( $1 \mid$ YR: CLT) +

dat $a=t$ empa)

$(1 \mid \mathrm{LC}: \mathrm{CLT})$ + ( 1| YR: LC: CLT) + (1| RPi d) ,

\# evel of significance

\#cal I function anova_Irt

anovalc $<$ anova_Irt(anovalc,fit.f1, fit.f 1c, "CLT")

\#nul I model for YR: LC

fi t. f $1 y|<| \operatorname{mer}(\operatorname{Tr} a i t \sim 1+(1 \mid Y R)+(1 \mid L C)+(1 \mid C L T)+$ ( 1|YR: CLT) +

dat $a=t$ empa)

$(1 \mid L C: C L T)+(1 \mid$ YR: LC: CLT) + ( 1| RPi d) ,

\# evel of significance

\#cal I function anova_Irt

anovalyl < anova_Irt ( anovalyl, fi t.f 1, fi t.f 1yl, "YR: LC")

\#nul I model for YR: CLT

fit.f 1yc $<1 \operatorname{mer}(\operatorname{Trait} \sim 1+(1 \mid \mathrm{YR})+(1 \mid \mathrm{LC})+(1 \mid \mathrm{CLT})+$ $(1 \mid$ YR: LC) +

dat $a=t$ empa)

$(1 \mid \mathrm{LC}: \mathrm{CLT})+(1 \mid$ YR: LC: CLT) + ( 1| RPi d) ,

\# evel of significance

\#cal I function anova_Irt

anovalyc < anova_I rt ( anovalyc, fi t.f 1, fi t. f lyc, "YR: CLT")

\#nul I nodel for LC: CLT

fit.f $1|c<| \operatorname{mer}(\operatorname{Trai} t \sim 1+(1 \mid \mathrm{YR})+(1 \mid \mathrm{LC})+(1 \mid \mathrm{CLT})+$ ( $1 \mid$ YR: LC) +

( 1|YR: CLT) +

( 1| YR: LC: CLT) + ( 1| RPi d), dat a=t empa)

\# evel of significance

\#cal I function anova_I rt

anovall c < anova_l rt ( anovall c, fit.f 1, fit.f Il c, "LC: CLT")

\#nul I model for YR: LC: CLT

fi t. f 1yl c $<\mid \operatorname{mer}(\operatorname{Tr}$ ai $t \sim 1+(1 \mid Y R)+(1 \mid L C)+(1 \mid C L T)+$ $(1 \mid$ YR: LC) +

$$
\begin{aligned}
& (1 \mid \text { YR: CLT) }+ \\
& (1 \mid L C: C L T)+(1 \mid R P i d), \text { dat a=t empa })
\end{aligned}
$$

\# evel of significance 


\section{\#cal I function anova_Irt}

anovalyl c <-

anova_I rt ( anovalyl c, fi t.f 1, fi t.f 1yl c, "YR: LC: CLT" )

\#nul I model for RP

fit.f $1 r<\mid \operatorname{mer}(\operatorname{Tr} a i t \sim 1+(1 \mid Y R)+(1 \mid L C)+(1 \mid C L T)+$ ( $1 \mid$ YR: LC) +

( 1| YR: CLT) +

( 1| LC: CLT) + ( 1| YR: LC: CLT), dat a=t empa)

\# evel of signi i cance

\#cal I function anova_Irt

anovalr $<$ anova_Irt( anovalyl r,fit.f 1,fit.flr, "RPi d")

\# Merge anova and I evel of si gnificance

anoval <- bi nd_rows( anovaly, anovall) \%\%

bi nd_rows (anovalc) \% \%

bi nd_rows( anovalyl) \% \% bi nd_rows(anovalyc) \% \%

bi nd_rows( anovalr) \% \%

bi nd_rows (anova1l c) \%\%i nd_rows ( anovalyl c)

anoval < as. dat a. frame( anova1)

\#Merge final out put

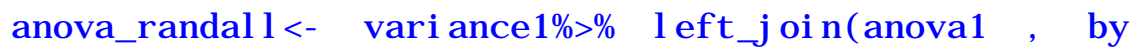
$=$ "sov" )

anova_randal I \$Pr_Chi sq[ anova_randal I \$st ddev $=0]<$ NA \#Print final output

pri nt ( anova_randal I )

\section{sov Vari ancest ddevPr_Chi sq}

YR:LC:CLT $49.72994 \quad 7.051946 \quad 8.894184 \mathrm{e}-03$

LC: CLT $0.00000 \quad 0.000000 \quad$ NA

RPid $73.91368 \quad 8.597306 \quad 4.145811 \mathrm{e}-07$

$\begin{array}{llll}\text { YR: CLT } & 0.00000 & 0.000000 & \text { NA }\end{array}$

YR: LC $\quad 57.81311 \quad 7.603494 \quad 7.872463 \mathrm{e}-02$

CLT 111. $69687 \quad 10.568674 \quad 1.386709 \mathrm{e}-03$

LC $699.56950 \quad 26.4493769 .083568 \mathrm{e}-03$

$\begin{array}{lllll}\text { YR } & 0.00000 & 0.000000 \quad N A\end{array}$

Resi dual 327.52638 18.097690 NA

Where sov $=$ source of variance, st ddev $=$ standard deviation, Pr_Chi sq

$=$ Chi-Square probability

In this example, the estimate of variance of random effects location $\mathrm{x}$ genotype (LC: CLT), year $x$ genotype (YR: LC) and year (YR) is zero. It represent overfitted model, meaning model is more complex than the data can support. Random effect variance estimated as zero is common with those random effects that have too few or small number of levels. The alternate option is to use Markov Chain Monte Carlo (MCMC) simulation using MCMCglmm package to get probability of random effects.

Fitness of ANOVA model for case 1 can be plotted using command 
pri int (anovacase1), where $\mathrm{x}$-axis is model predicted value and $\mathrm{y}$-axis is residual value (Figure 2). The uniform distribution of fitted residuals on both side of the reference line (value $=0$ ) confirms the goodness of fit.

The best linear unbiased predictor (BLUP) of random effects can be extracted using $r$ anef ( ) function of lme4 package. BLUPs are estimates of random effects. They allow us to account environmental factors in our model and missing data; and can be used for making selection. BLUP tend to "shrunk" towards the population mean relative to their fixed effects estimates. RGxE computes BLUP of individual genotypes and generate user friendly output in "dat a. f r ame" class using dplyr and tidyr packages (see below code).
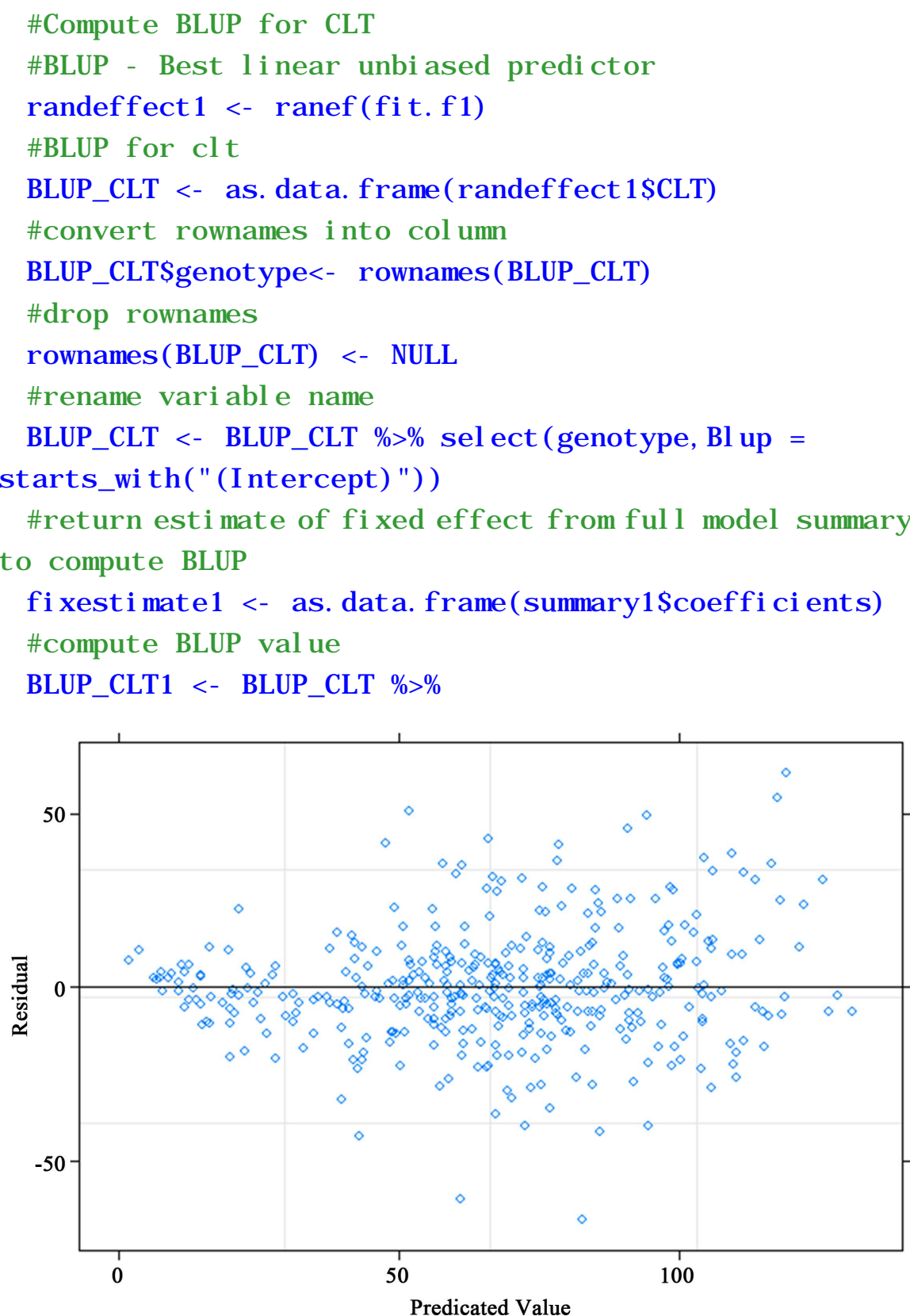

Figure 2. Residual plot for Case 1 of ANOVA model where genotype, location, year and replication are treated as random effect. 


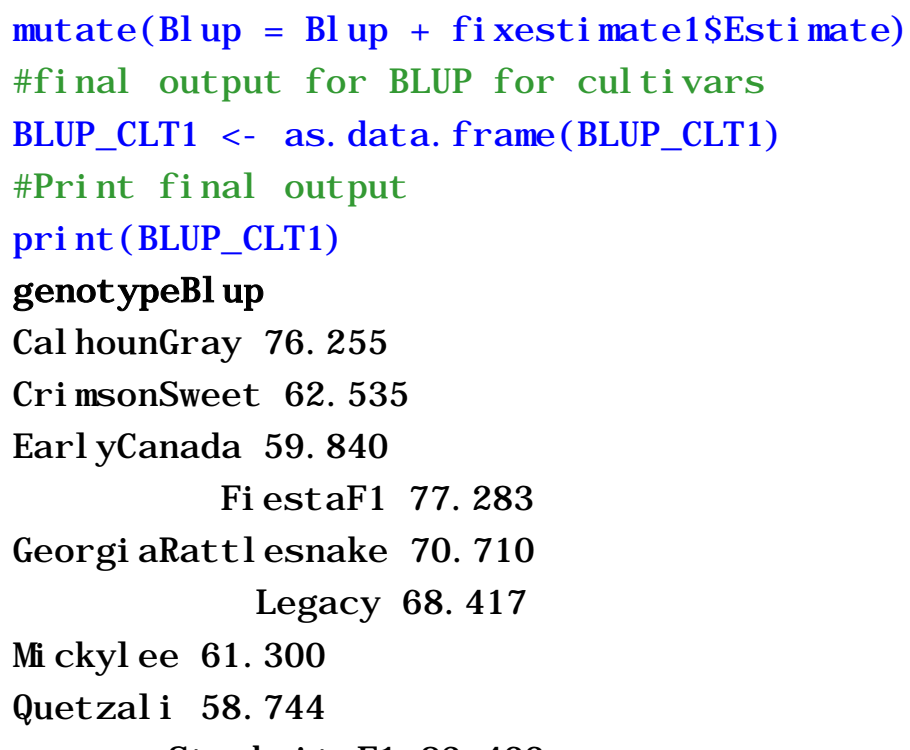

St arbri teF1 83. 422

Sugar Baby 51. 169

Where BLUP = best linear unbiased predictor

Similarly, remaining four cases of ANOVA model can be independently computed using code presented in Supplemental Material.

\subsubsection{Descriptive Statistics}

A new additional variable environment (ENV) is created and quality check of missing value is performed in dataset "t empa2" using dplyr package. Environment is location-year combination, which is highlighted is below code. RGxE validates structure of dataset "t empa2" as it serves input data for descriptive and other statistics (Figure 1).

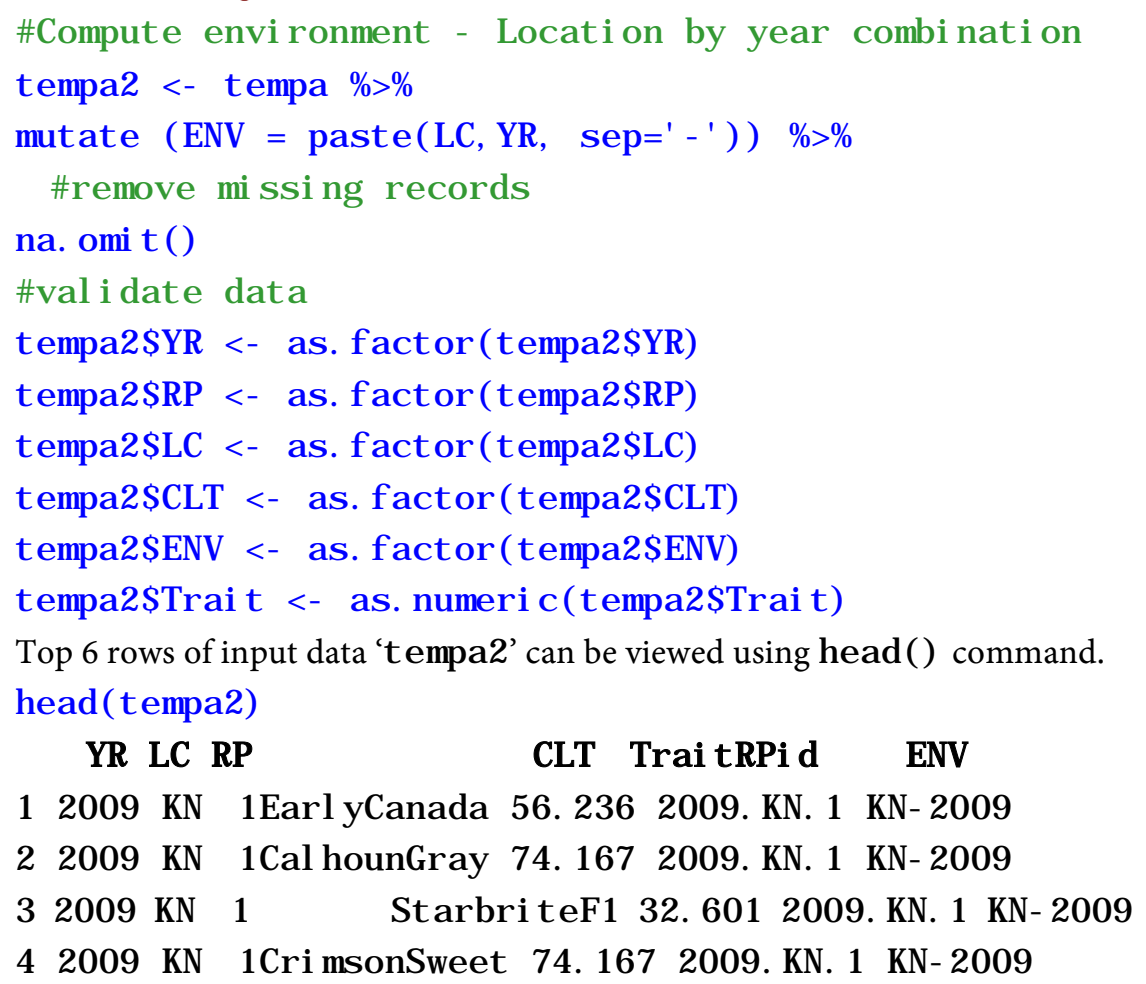


52009 KN 1Geor gi aRattl esnake 64. 794 2009. KN. 1 KN- 2009 62009 KN $1 \quad$ Fi estaF1 70. 907 2009. KN. 1 KN- 2009

Descriptive statistics including count, minimum (min), maximum (max), mean, sum, median, variance (var), standard deviation (sd), and coefficient of variation (cv) are computed using dplyr package. Using tidyr package results of descriptive statistics are transposed in user friendly layout so that researchers can interpret them easily (see Supplemental Material for descriptive statistics outputs). RGxE generates following descriptive statistics.

- Trait mean over genotype and environment

- Trait mean and sd over genotype and year

- Trait mean, cv, sd and sum over genotype and location

- Trait mean, sd, and sum over genotype, location and year

- Trait mean over genotype, location and replication

- Trait mean over location and year

- Trait mean over location and replication

- Trait count, min, max, mean, sum, median, var, and sd over location

- Trait count, min, max, mean, sum, median, var, and sd over year

- Trait count, min, max, mean, sum, median, var, and sd over genotype

- Trait count, min, max, mean, sum, median, var, and sd over environment

\subsubsection{Univariate Stability Statistics}

Among univariate stability statistics, RGxE generates output of regression slope $\left(b_{i}\right)$, deviation from regression $\left(S_{d}^{2}\right)$, Shukla's sigma $\left(\sigma_{i}^{2}\right)$, ssquares, Wricke's ecovalence $\left(W_{i}\right)$ and Kang's statistics $\left(Y S_{i}\right)$. RGxE regresses the response of genotype against the environmental index to compute regression slope $\left(b_{i}\right)$, deviation from regression $\left(S_{d}^{2}\right), T$-test on regression slope $\left(\mathrm{H}_{0}: b_{i}=1\right)$ and $F$-test on deviation from regression $\left(\mathrm{H}_{0}: S_{d}^{2}=0\right)$. The level of significance of $T$-test and $F$-test is computed using I $\mathrm{m}$ ( ) function of R [19], and dplyr and tidyr packages. The level of significance at $0.05,0.01$ and 0.001 is represented by “*”, "***”, "***”; respectively. Environmental index is average performance of all genotypes in each environment. St abi I i ty. par ( ) function of agricolae package is used to compute Shukla's sigma $\left(\sigma_{i}^{2}\right)$, ssquares, Wricke's ecovalence $\left(W_{i}\right)$ and Kang's statistics $\left(Y S_{i}\right)$. For selection of stable genotype, user can independently compute univariate stability statistics while feeding required input data (t empa2) in below code. Top 6 rows of input data "t empa2" is presented in section 4.2 descriptive statistics.

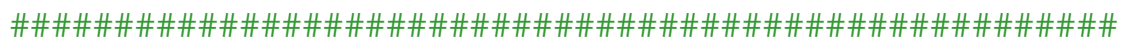

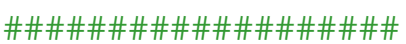

\#\# Compute uni vari ate stability statistics -

regression anal ysis \#\#

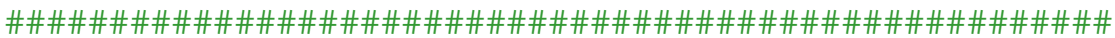

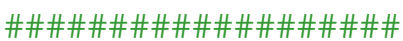

\#Comput e regressi on ( $\mathrm{sl}$ ope) and devi at i on from regressi on

\#compute envi ronment al index 
dsterm- tempa2 \%\%

group_by ( EN, RP, YR, LC) \% \%

summarize ( ENVTrai $t=\operatorname{mean}(\operatorname{Tr}$ ai $t$, na. $r m F A L S E)$ )

dst $02<$ tempa2 \%\%

l ef $t$ j oi $n$ (dsterm by=c("ENV", "RP" ) ) \%\% \# \# $\mathrm{t}$ j oi $n$ on mul ti pl e col ums

arrange (CLT) \% \%

rename $(Y R=Y R . x, L C=L C . x)$

\# it model

fit_model $<$ dst $02 \% \%$

group_by(CLT) \%\%\#group regressi on anal ysi s by cul ti var do ( model =f m(Trai t -ENVTrai t + ENV + RP, dat $a=$ ) )

\#par arret er esti mates

param me- as. data.frame(fit_model \% \% ti dy (nodel ))

gl ancel me- as. data.frame( fit_model \% $\%$ gl ance( nodel ))

augment I mK- as. data.frame(fit_model \% \%augment (model )) out nsed < I appl y( fi t_model \$rodel, anova) \#anova out put out nsed2 « as. data.frame(do. call(rbind, out nsed))

\#convert list into data.frame

\#convert rownames i nt o col umn

out nsed2\$SOV $<$ rownames ( out msed2)

\# droprownanes

r ownames ( out nsed2) <- NULL

\#renove numeric val ues from string of rownames using

f unct i on gsub

out nsed $2<$ out nsed $2 \% \%$ mut at e( SOV = gsub( "\\d+", " ", SOV) )

\#extract uni que cultivar name and merge to out msed2 dat as et

genotypes $<$ dst $02 \% \%$ sel ect (CLT) \% \%di st i nct (CLT) \% \% arr ange( CLT)

\#Stack 4 ti mes to match number of rows wi th out nsed2 dat aset

genotypes $1<$ genotypes \%\%i nd_rows(genot ypes) \%\%

bi nd_rows(genot ypes) $\%$ bi nd_rows(genot ypes) $\% \%$ ar r ange( CLT)

\#attach I ist of cul ti vars to out msed2

out nsed $3<$ as. data.frame( out nsed2 \% $\%$

bi nd_col s(genot ypes 1 ))

\# $r$ anspose out nsed3

out nsed4 < out nsed3 \%\%

sel ect (CLT, SOV, MS =starts_wi th( "Mean")) \%\% \#r ename vari abl es

filter (SOV ! = "RP")

\# $\mathrm{r}$ anspose MS val ues 
MSDS < out nsed4 \% \%

spread ( SOV, MS) $\% \%$ \#transpose using I i brary ti dyr arrange ( CLT)

\#Transpose degress of freedons for F-test

FDS3 $<$ out nsed3 \%\%

filter ( SOV ! = "RP") \% \%

sel ect (CLT, SOV, Df) \% \%

spread ( SOV, Df) \% \% \#ranspose using I i brary tidyr

rename (DF_ENTTrait $=$ ENVTrait, DF_Resi dual $s=$ Resi dual s,

$$
\text { DF_ENV = ENV) }
$$

\#Subset par ameters - param m dat aset

REGCOEFGS $<-$ par am $\mathrm{m} \% \%$

filter (term = "ENVTrait") \% $\%$

sel ect (-statistic, - p. val ue)

\#Test and I evel of significance of regression and devi at $i$ on from regressi on

\#Merge MSDS, FDS3, REGCOEFGS

sl ope<- MSDS \% \% i nner_j oi n (REGCOEFGS, by = "CLT") \% \% i nner_j oi n (FDS3, by = "CLT") \% \%

rename ( MSE $=$ Resi dual s, LREGMS=ENVTr ai t, DEVLMS $=E N$,

$\mathrm{BI}=$ est i mate, STDERR = std. error)

\# est signi fi cance I evel s

sl ope1 < sl ope $\% \%$

mit at e $\left(T_{-} H_{01}=(B I-1) /\right.$ STDERR, \#Nul I Hypot hesi s f or sl ope $=1$

PT_H01 $=2 *$ pt $\left(-\operatorname{abs}\left(T_{-}\right.\right.$H01), DF_Resi dual s),

F_DEVREG=DEVLMS/MSE, \#NULL HYPOTHESI S:

PREDI CTED- ACTUAL $=0$

PF_HOO= 1-pf $\left(F_{-}\right.$DEVREG, DF_ENV, DF_Resi dual s $\left.)\right)$

\#add I egend for I evel of signi i cance

sl ope2 < sl ope1 \%\%

mit ate (SI G_SLOPE $=$ i fel se(PT_H01 $<=0.001, " * * * "$, i f el se( PT_H01 $<=0.01, " * * *$,

i f el se(PT_HO1 $<=0.05, " * ", "$ " )) )) $\% \%$

mit at e (SI G_DEVREG = i f el se( PF_HOO $<=0.001$, "***",

i f el se( PF_HOO $<=0.01, " * * "$,

i f el $\mathrm{se}\left(\mathrm{PF}_{-} \mathrm{HOO}<=0.05, " * ", "\right.$ " )) ))

\# i nal regression out put

opt i ons ( di gi t s $=5$ )

uni vari ate2 $<$ sl ope2 \%\%

mut at e ( SLOPE = past e( BI , SI G_SLOPE, sep=" ") ,

DEVREG = past e( DEVLMS, SI G_DEVREG, sep=' " ) ) \% \%

sel ect (CLT, SLOPE, DEVREG ) 


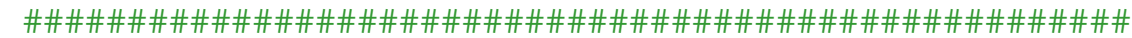

\#\#\#\#\#\#\#\#\#\#\#\#\#\#\#

\# Compute uni vari ate stabi l ity stati stics - shukl a, ecoval ence, YS \#

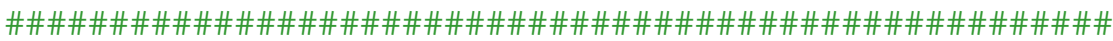

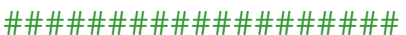

\#Comput e Shukl a, Wri ckeEcoval ense, Kangs YS

repno $<$ tempa $\% \%$

summarise (total_rep = n_di sti nct(RP)) \#count total

number of rep

dstgl $<$ tempa2 \%\%

group_by (CLT, LC) \% \%

\#Summari ze genotype perfor mance across I ocat i ons

summarize ( $\operatorname{Tr}$ ai $t=\operatorname{mean}(\operatorname{Tr}$ ai $t$, na. $r$ mFALSE))

dstgl $1<$ dstgl $\% \%$

spread ( LC, Trait) \# \#ranspose val ues

\#convert i nto dat a frame so that row cont ai ni ng struct ure i nf or mati on is del eted

dstgl $2<$ as. dat a.frame (dstgl 1$)$

\#create rownames

rownames $($ dstgl 2) $<$ dstgl $2[, 1]$

shukl $a<$ dstgl 2[, - 1]

\#compute MS error term

t empa3 $<$ gl m $\operatorname{Tr}$ ai t $\sim$ LC + YR + LC: YR + RP \% n\% ( LC: YR)

$+\mathrm{CLT}+\mathrm{CLT}: \mathrm{LC}+$

dat $\mathrm{a}=\mathrm{t}$ empa2 )

CLT: YR + CLT: LC: YR, family = gaussian ,

\#nodel summary

summary 1 < summary. gl m( t empa3)

\#Error SS

error_ss $<$ as. dat a. f rame( summar y 1 \$devi ance)

error_ss $1<$ error_ss $\% \%$

\#r ename vari abl e

sel ect (Devi ance = starts_wi th("summary"), everythi ng( ))

\#Error DF

error_df $<$ as. dat a. f r ame( summary $1 \$ d f$. resi dual )

error_df $1<$ error_df $\% \%$

\#r ename vari abl e

sel ect ( Df = starts_wi th("summary"), everythi ng( ))

\#MS of error

msel <- as. dat a.frame( error_ss1/error_df 1)

mse $<$ msel \%\%

\#r ename vari abl e 


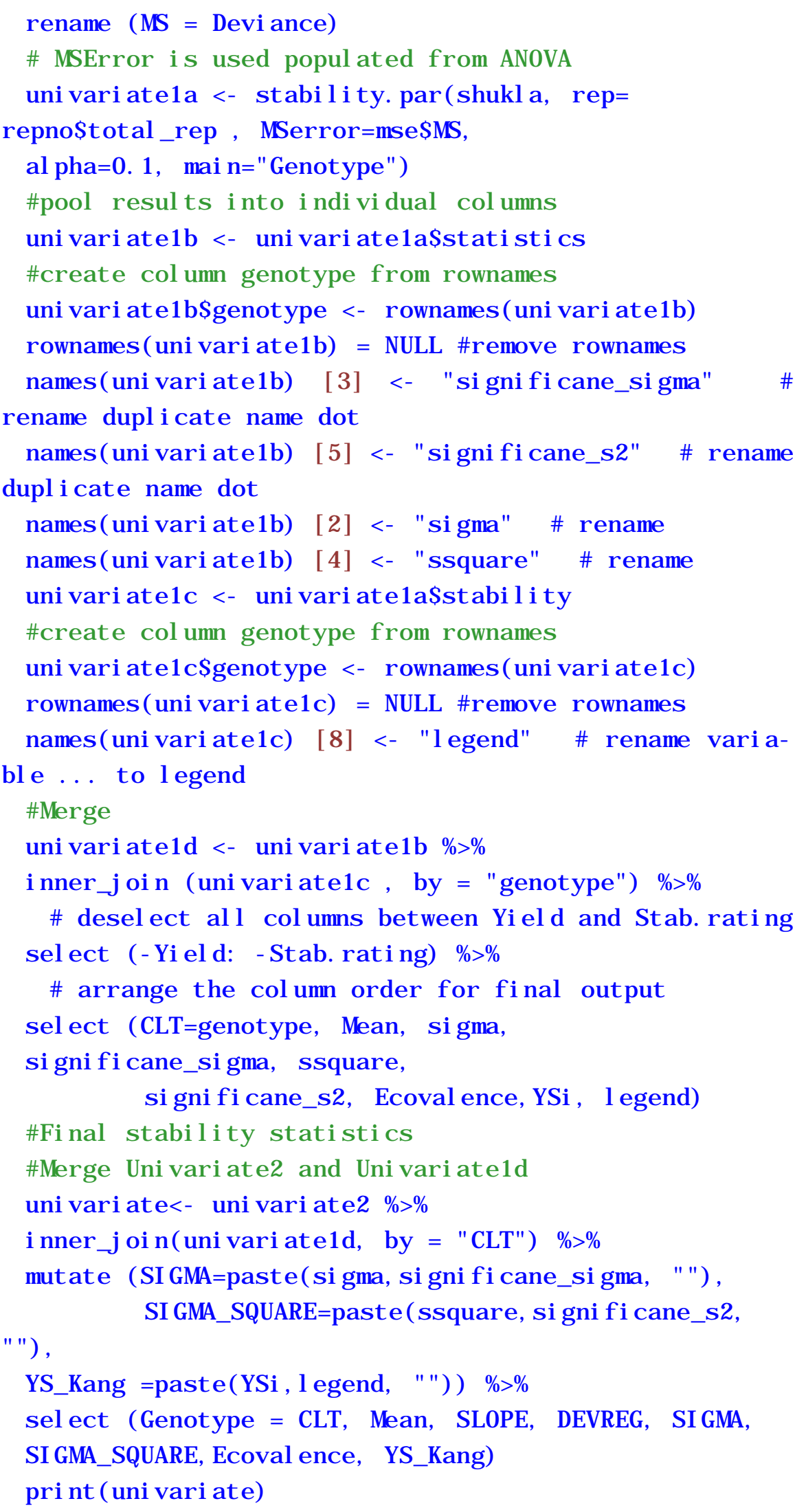

Genot ype Mean SLOPE DEVREG SI GMA SI GMA_SQUARE Ecoval enceYS_Kang 
Cal hounGray 77.349 1. $32 \quad 124.67 \quad 61.35$ ns $\quad 15.76$ ns 279. $7510+$

Cri nsonSweet 62.0131 .36 1450.04*** 439.12 ns 567.99 ns 1488. $64 \quad 4$

Ear l yCanada $59.000 \quad 0.32 * 686.25 * \quad 253.23 n s \quad 285.37$ ns 893. $77 \quad 2$

$\begin{array}{lllll}\text { Fi est aF1 } & 78.498 & 1.58 & 657.87 & 300.29\end{array}$

385. 99 ns 1044. $35 \quad 11+$

$\begin{array}{llll}\text { Geor gi aRatt I esnake } 71.151 & 0.92 & 220.06 & 52.21\end{array}$ ns 44. 86 ns 250.52 $8+$

$\begin{array}{lllll}\text { Legacy } & 68.588 & 1.13 & 428.07 & 287.39 \\ \text { ns }\end{array}$

262. 49 ns 1003. $10 \quad 7+$

M ckyl ee 60.6320 .59 705.48* 188.11 ns 195.13 ns 685. $37 \quad 3$

$\begin{array}{llllll}\text { Quetzal i } 57.775 & 0.97 & 96.53 & 82.81 & \text { ns } & 86.10\end{array}$ 348. $42 \quad 1$

$\begin{array}{lllll}\text { StarbriteF1 } & 85.360 & 1.29 & 221.14 & 157.24\end{array}$

78. 37 ns $586.61 \quad 12+$

Sugar Baby $\begin{array}{lllll}49.307 & 0.50 * & 332.18 * & 264.19 n s & 308.43 \\ \text { ns }\end{array}$ 928. $84-1$

Where SLOPE = regression slope, DEVREG $=$ deviation from regression, SI GMA = Shukla's sigma, SI GMA_SQUARE = ssquares, Ecoval ence = Wricke's ecovalence, YS_Kang $=$ Kang's statistics, ns $=$ non-significant, $+=$ indicate stable genotype according to Kang's stability statistics

\subsection{Location Value Statistics}

Input data "t empa2" is used to calculate genotype $F$ ratio across location and environment; correlation of location with average location performance; and location cluster analysis.

\subsubsection{Genotype $\boldsymbol{F}$ Ratio across Location and Environment; and Correlation among Location and Average Location}

RGxE computes analysis of variance by location using I $\mathrm{m}$ ) function to get the genotype $\mathrm{F}$ values across location. When the mean of all genotypes are equal then the $F$ ratio will be close to 1 . The high genotype $F$ value indicates high discriminating ability for that location. Similarly, Pearson's test of correlation of locations with average location is computed using cor.test ( ) function of R built in stats package [19]. Function cor . t est ( ) provide level of significance of correlation and the level of significance at $0.05,0.01$ and 0.001 is represented by “*”, “**”, “***»; respectively. RGxE generates user friendly output for genotype $F$ ratio across location and environment; and correlation of location with average location performance using dplyr and tidyr packages as shown in below code.

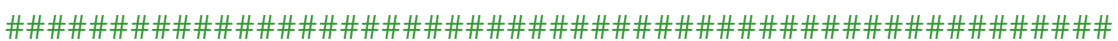

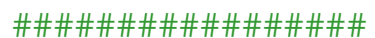




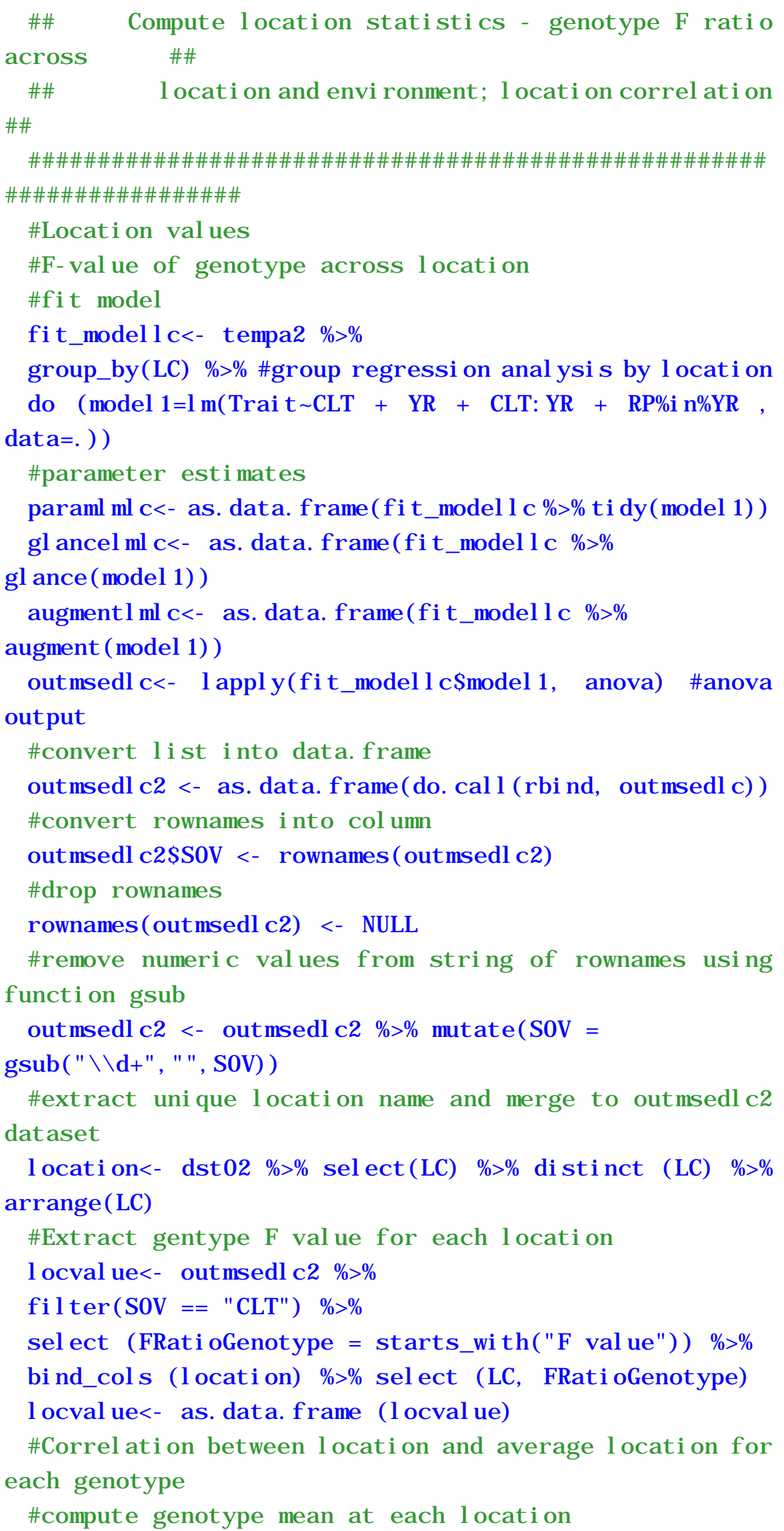


gl crean1 $<$ tempa $\% \%$

group_by (CLT, LC) \% \%

summarize ( gl cmean $=\operatorname{mean}(\operatorname{Tr} a i t$, na. $r m F A L S E)) \%$

as. data.frame( sel ect (CLT, LC, gl cmean))

\#compute genotype mean across al I location -average

I ocat i on

gmean1 $<$ tempa2 \%\%

group_by (CLT) \% \%

summari ze ( grean = mean( $\operatorname{Tr}$ ai $t$, na. $r$ mFALSE) $) \%$

as. dat a. frame( sel ect (CLT, gmean))

\#merge I ocation mean with average I ocation for each genot ype

I grean< - gl crean1 \%\%

I ef t_j oi n( grean1, by="CLT" ) \% \%

arrange( LC) \% \% sel ect ( - CLT)

\#compute correl ation wi th I evel of signi ficance

I cgcor $r<$ I gmean $\% \%$

group_by( LC) \%\%

do( t i dy (cor. t est (. \$gl cmean, . \$gmean, met hod = c( "pear son" ) )) )

I cgcorr $1<$ I cgcorr \% $\%$

sel ect ( LC, Corr_Val ue = starts_wi th ("esti mate"),

Pval ue = starts_wi th( "p. val ue") )

\#post process correl ation val ue

I cgcorr $2<$ I cgcorr $1 \% \%$

mit at e ( SI G_CORR = i f el se( Pval ue $<=0.001$, "***",

i f el $\mathrm{se}$ ( Pval ue $<=0.01, " * * "$,

i f el se( Pval ue<=0.05, "*", " "))) )

\#concatenate p val ue symbol wi th correl ati on val ue

I cgcorr $3<$ I cgcorr $\% \%$

mit ate ( LocCorrel at i on=paste(Corr_Val ue, SI G_CORR, sep=" ") ) \% \%

sel ect ( LC, LocCorrel at i on)

I cgcorr $3<$ as. data. frame $($ I cgcorr 3$)$

\#Fi nal I ocation val ue table for output

\#compute I ocati on mean

Locmean $<$ tempa2 \%\%

group_by ( LC ) \% \%

summarize ( $\operatorname{Tr}$ ai $t=\operatorname{mean}(\operatorname{Tr}$ ai $t$, na. $r$ mALSE) $) \%$

sel ect ( LC, Mean = starts_wi th("Trait"))

Locmean<- as. dat a.f r ame( Locmean)

\#nerge al I I ocati on val ue outputs for print

Locat i onVal ue $<$ - Locmean $\% \%$

i nner_j oi n ( l ocval ue, by = "LC") \% \% 
i nner_j oi n( I cgcorr3, by = "LC" ) \% \%

rename ( Locati on $=\mathrm{LC}$ )

pri nt ( Locat i onVal ue)

\section{Locat $\mathrm{i}$ on Mean FRat $\mathrm{i}$ oGenot ypeLocCor rel at $\mathrm{i}$ on}
Cl 61.040
4. $18040.95^{* * *}$

FL 100. 153

2. $2579 \quad 0.86 * *$

$\begin{array}{llll}\text { KN } & 63.786 & 4.6964 & 0.90 * * * \\ \text { SC } & 82.685 & 6.8813 & 0.88 * * * \\ \text { TX } & 27.173 & 2.9966 & 0.89 * * *\end{array}$

Wher eFRat i oGenot ype = genot ype $\mathrm{F}$ rat i 0 , LocCor rel at i on = correl at $\mathrm{i}$ on of I ocat $\mathrm{i}$ on with average I ocat $\mathrm{i}$ on

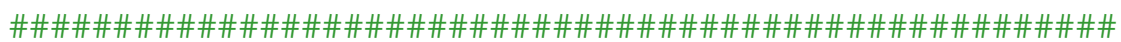

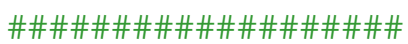

\#\#\#-val ue of genotype across envi ronmen \#\#

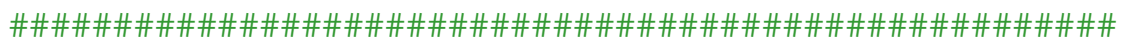

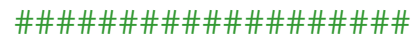

\# it model

fit_model en $<$ tempa2 \% $\%$

group_by(ENV) \%\%\#group regressi on anal ysi s by I ocat i on do ( model $2=1 \mathrm{~m}(\operatorname{Tr}$ ai $\mathrm{t} \sim \mathrm{CLT}+\mathrm{RP}$, dat $\mathrm{a}=$ ) )

\#par amet er esti mates

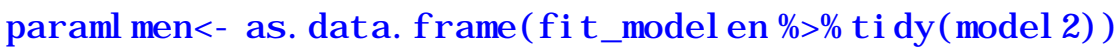
$\mathrm{gl}$ ancel men<- as. data.frame( $\mathrm{fit}$-model en $\% \%$

gl ance( nodel 2))

augment I men $<$ as. data.frame( fit_model en $\% \%$

augment ( model 2))

out nseden<- I appl y( $\mathrm{fit}$ _model en\$rodel 2, anova) \#anova out put

\#convert l ist i nto data.frame

out mseden $2<$ as. dat a. frame( do. cal I ( $r$ bi nd, out mseden))

\#convert rownames i nto col um

out nseden $2 \$ S O V<$ rownames ( out nseden 2 )

\# droprownarres

rownames ( out ns eden 2$)<$ NULL

\#renove numeric val ues fromstring of rownames using

functi on gsub

out nseden $2<$ out nseden $2 \% \%$ mit at el SOV = gsub( "\\d+", " ", sOV) )

\#extract uni que envi ronment name and merge to out nseden2 dat aset

envi ronment < dst $02 \% \%$ sel ect (EM) \% \% di sti nct

( ENV) $\% \%$ arrange( ENV)

\#Ext ract gent ype $F$ val ue for each I ocation 
I ocval ue2 <- out mseden2 \%\%

filter( $\mathrm{SOV}=$ "CLT") \% $\%$

sel ect (FRati oGenotype = starts_wi th("F val ue")) \%\%

bi nd_col s (envi ronment) \% \%sel ect ( ENV, FRat i oGenot ype)

I ocval ue2 <- as. data. frame (I ocval ue2)

print ( I ocval ue2)

EN FRat i oGenot ype

$\begin{array}{ll}\text { Cl }-2009 & 2.4015 \\ \text { Cl }-2010 & 3.3665 \\ \text { FL- } 2009 & 2.6914 \\ \text { FL- } 2010 & 1.7231 \\ \text { KN- } 2009 & 1.9999 \\ \text { KN- } 2010 & 6.3971 \\ \text { SC- } 2009 & 2.8729 \\ \text { SC- } 2010 & 8.0454 \\ \text { TX- } 2009 & 2.5003\end{array}$

TX- $2010 \quad 1.4619$

Where ENV = environment, FRat i o Genot ype = genotype $F$ ratio

\subsubsection{Location Cluster Analysis}

Hierarchical cluster analysis for location relatedness is computed using hcl ust ( ) function of R built in stats package [19]. The arguments passed to hcl ust ( ) function include Euclidean distance computed from di st ( ) function and Ward's method. Function di st () of R built in stats package [19] computes and return the distance matrix between rows of a data matrix. Tree or dendogram of cluster analysis is generated using $\mathrm{pl}$ ot ( ) function, of R built in graphics package [19], as shown in below code.

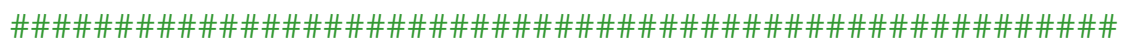
\#\#\#\#\#\#\#\#\#\#\#\#\#\#

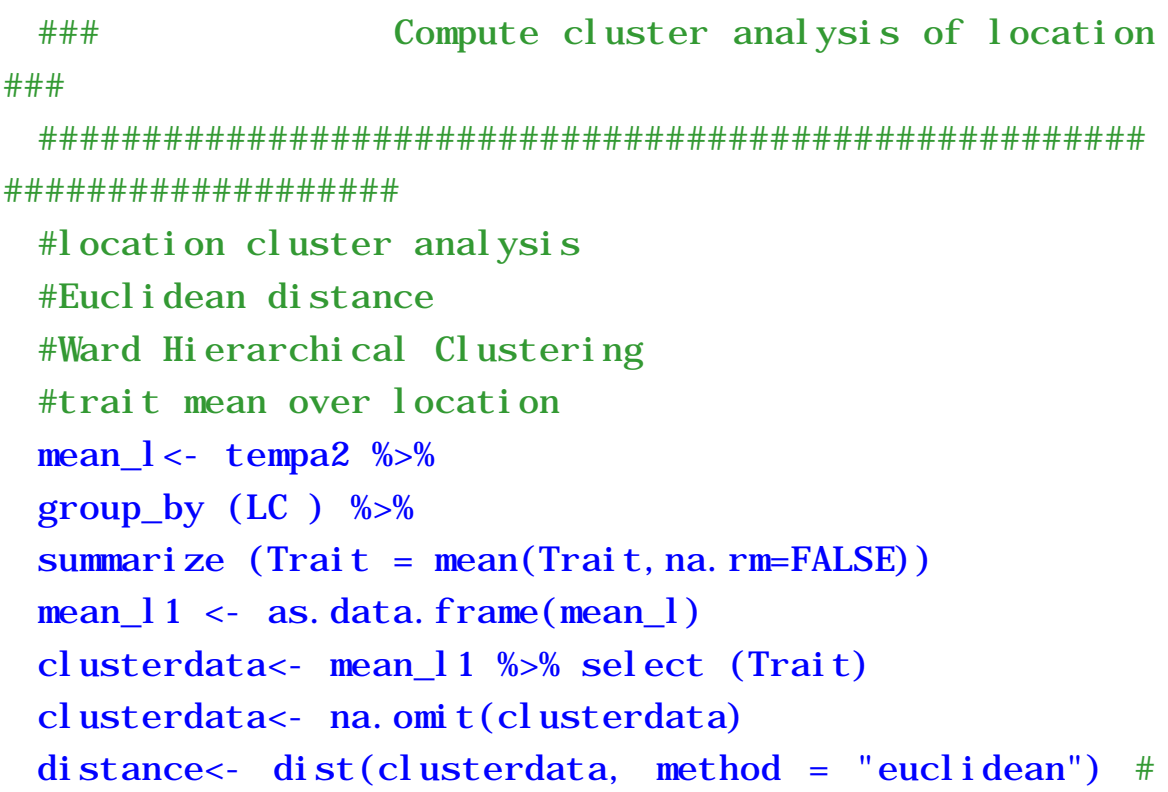




\section{di stance matrix \\ hcl ust er $<$ hcl ust ( $d=$ di st ance, met hod=" war d. D" ) \\ l ocat i oncl ust er $<$ pl ot ( hcl ust er, I abel s=mean_I 1\$LC) \# di spl ay dendogram}

\section{Final Output}

After all computation is over, RGxE clears the Console Window of $\mathrm{R}$ studio then saves the output using si nk() function along with the system date and time using Sys. t i me( ) function of R built in base package [19]. RGxE auto saves the output (output name = "RGXEOut put") in folder which is defined inset $w d()$ command in the beginning of the program. Program gives user option to save results in .csv (RGXEOut put. CSV) or .txt (RGXEOut put . t xt) format. Output, in .txt format, from sample input data generated by RGxE is presented in Supplemental Material. Additionally, RGxE prints the output in Console Window of R studio.

\section{Result Interpretation}

Interpretation of univariate stability statistics is presented in Supplemental Material. Additionally, studies published on genotype stability [27] and location value [28] used SASGxE program [17], which is equivalent to RGxE program. Similarly, research study on stability of watermelon fruit quality traits used RGxE program [29]. Thus, these studies can serve as source of RGxE output interpretation. Also, interpretation of RGxE and SASGxE program is available at available at http://cuke.hort.ncsu.edu/cucurbit/wehner/software.html.

\section{References}

[1] Dia, M., Weindorf, D., Thompson, C., Cummings, H., Cacovean, H. and Rusu, T. (2009) Spatial Distribution of Heavy Metals in the Soils of Erath County, Texas. Studia Universitatis Babes-Bolyai, Geographia, No. 2, 99-114.

[2] Li, Y., Gibson, J.M., Jat, P., Puggioni, G., Hasan, M., West, J.J., Vizuete, W., Sexton, K. and Serre, M. (2010) Burden of Diseases Attributed to Anthropogenic Air Pollution in the United Arab Emirates: Estimates Based on Observed Air Quality Data. Science of the Total Environment, 408, 5784-5793. https://doi.org/10.1016/j.scitotenv.2010.08.017

[3] Jat, P. and Serre, M.L. (2016) Bayesian Maximum Entropy Space/Time Estimation of Surface Water Chloride in Maryland Using River Distances. Environmental PolIution, 219, 1148-1155. https://doi.org/10.1016/j.envpol.2016.09.020

[4] Weindorf, D.C., Sarkar, R., Dia, M., Wang, H., Chang, Q., Haggard, B., McWhirt, A. and Wooten, A. (2008) Correlation of X-Ray Fluorescence Spectrometry and Inductively Coupled Plasma Atomic Emission Spectroscopy for Elemental Determination in Composted Products. Compost Science \& Utilization, 16, 79-82. https://doi.org/10.1080/1065657X.2008.10702361

[5] Weindorf, D., Rinard, B., Zhu, Y., Johnson, S., Haggard, B., McPherson, J., Dia, M., Spinks, C. and McWhirt, A. (2008) High Resolution Soil Survey of Capulin Volcano National Monument, New Mexico. Soil Horizons, 49, 55-62.

https://doi.org/10.2136/sh2008.3.0055 
[6] Dia, M., Wehner, T.C., Hassell, R., Price, D.S., Boyhan, G.E., Olson, S., King, S., Davis, A.R., Tolla, G.E., Bernier, J., Juarez, B., Sari, N., Solmaz, I. and Aras, V. (2012) Stability of Fruit Yield in Watermelon Genotypes Tested in Multiple US Environments. Proceedings of the Xth EUCARPIA Meeting on Genetics and Breeding of Cucurbitaceae, Antalya, Turkey, 15-18 October 2012, 84-88.

[7] Dia, M., Wehner, T.C., Hassell, R., Price, D.S., Boyhan, G.E., Olson, S., King, S., Davis, A.R., Tolla, G.E., Bernier, J., Juarez, B., Sari, N., Solmaz, I. and Aras V.(2012) Mega-Environment Identification for Watermelon Yield Testing in the USProceedings of the Xth EUCARPIA Meeting on Genetics and Breeding of Cucurbitaceae, Antalya, Turkey, 15-18 October 2012, 385-390.

[8] Kumar, R., Dia, M. and Wehner, T.C. (2013) Implications of Mating Behavior in Watermelon Breeding. HortScience, 48, 960-964.

[9] Yan, W., Pageau, D., Frégeau-Reid, J. and Durand, J. (2011) Assessing the Representativeness and Repeatability of Test Locations for Genotype Evaluation. Crop Science, 51, 1603-1610. https://doi.org/10.2135/cropsci2011.01.0016

[10] Smith, A.B., Cullis, B.R. and Thompson, R. (2005) The Analysis of Crop Cultivar Breeding and Evaluation Trials: An Overview of Current Mixed Model Approaches. Journal of Agricultural Science, 143, 449-462. https://doi.org/10.1017/S0021859605005587

[11] Wricke, G. (1962) Evaluation Method for Recording Ecological Differences in Field Trials. Z Pflanzenzücht, 47, 92-96.

[12] Shukla, G.K. (1972) Genotype Stability Analysis and Its Application to Potato Regional Trails. Crop Science, 11, 184-190.

[13] Kang, M.S., Miller, J.D. and Darrah, L.L. (1987) A Note on Relationship between Stability Variance and Ecovalence. Journal of Heredity, 78, 107. https://doi.org/10.1093/oxfordjournals.jhered.a110322

[14] Kang, M.S. (1993) Simultaneous Selection for Yield and Stability in Crop Performance Trials: Consequences for Growers. Agronomy Journal, 85, 754-757. https://doi.org/10.2134/agronj1993.00021962008500030042x

[15] Mekbib, F. (2003) Yield Stability in Common Beans (Phaseolus vulgaris L.) Genotypes. Euphytica, 130, 147-153.

[16] Fan, X.M., Kang, M., Chen, H., Zhang, Y., Tan, J. and Xu, C. (2007) Yield Stability of Maize Hybrids Evaluated in Multi-Environment Trials in Yunnan, China. Agronomy Journal, 99, 220-228. https://doi.org/10.2134/agronj2006.0144

[17] Dia, M., Wehner, T.C. and Arellano, C. (2016) Analysis of Genotype $\times$ Environment Interaction $(\mathrm{G} \times \mathrm{E}$ ) Using SAS Programming. Agronomy Journal, 108, 1838 1852. https://doi.org/10.2134/agronj2016.02.0085

[18] RStudio Team (2015) RStudio: Integrated Development for R. RStudio, Inc., Boston, MA (Computer Software v0.98.1074). http://www.rstudio.com/

[19] R Core Team (2015) R: A Language and Environment for Statistical Computing. R Foundation for Statistical Computing, Vienna, Austria. http://www.R-project.org/

[20] Wickham, H. and Francois, R. (2015) dplyr: A Grammar of Data Manipulation. R Package Version 0.4.3. http://CRAN.R-project.org/package=dplyr

[21] Wickham, H. (2016) tidyr: Easily Tidy Data with 'spread()' and 'gather()' Functions. R package Version 0.4.1. http://CRAN.R-project.org/package=tidyr

[22] Robinson, D. (2015) broom: Convert Statistical Analysis Objects into Tidy Data Frames. R Package Version 0.4.0. http://CRAN.R-project.org/package=broom

[23] Mendiburu, F.D. (2015) agricolae: Statistical Procedures for Agricultural Research. 
R Package Version 1.2-3. http://CRAN.R-project.org/package=agricolae

[24] Bates, D., Maechler, M., Bolker, B. and Walker, S. (2015) Fitting Linear Mixed-Effects Models Using lme4. Journal of Statistical Software, 67, 1-48. https://doi.org/10.18637/jss.v067.i01

[25] Singmann, H., Bolker, B. and Westfall, J. (2015) afex: Analysis of Factorial Experiments. R Package Version 0.15-2. http://CRAN.R-project.org/package=afex

[26] Maechler, M., Rousseeuw, P., Struyt, A. and Hubert, M. (2015) cluster: Cluster Analysis Basics and Extensions. R Package Version 2.0.1.

[27] Dia, M., Wehner, T.C., Hassell, R., Price, D.S., Boyhan, G.E., Olson, S., King, S., Davis, A.R. andTolla, G.E. (2016) Genotype $\times$ Environment Interaction and Stability Analysis for Watermelon Fruit Yield in the U.S. Crop Science, 56, 1645-1661. https://doi.org/10.2135/cropsci2015.10.0625

[28] Dia, M., Wehner, T.C., Hassell, R., Price, D.S., Boyhan, G.E., Olson, S., King S., Davis, A.R. and Tolla, G.E. (2016) Values of Locations for Representing Mega-Environments and for Discriminating Yield of Watermelon in the U.S. Crop Science, 56, 1726-1735. https://doi.org/10.2135/cropsci2015.11.0698

[29] Dia, M., Wehner, T.C., Perkins-Veazie, P., Hassell, R., Price, D.S., Boyhan, G.E., Olson, S., King, S., Davis, A.R., Tolla, G.E., Bernier, J. and Juarez, B. (2016) Stability of Fruit Quality Traits in Diverse Watermelon Cultivars Tested in Multiple Environments. Horticulture Research, 3, Article No. 16066.

https://doi.org/10.1038/hortres.2016.66 


\section{Supplemental Material}

The supplemental material available online includes the RGxE program, instructions for user enetered field needed in RGxE program, independent module of ANOVA model case 2 to 5 (Table 1), interpretation of univariate stability statistics, example input data and output from example input data generated from RGxE program. Additionally, interpretation of univariate and multivariate statistical analysis is provided in [17].

http://cucurbitbreeding.com/wp-content/uploads/2016/05/RGxE17Suppleme nt.pdf

\section{List of Abbreviations}

AMMI = Additive main effects and multiplicative interaction model

ANOVA $=$ Analysis of variance

BLUP $=$ Best linear unbiased prediction

CLT $=$ Cultigen or genotype

CRAN $=$ Comprehensive R Archive Network

$\mathrm{CSV}=$ Comma Separated Value

$\mathrm{CV}=$ Coefficient of variation

$\mathrm{DF}=$ Degrees of freedom

ENV = Environment (location - year combination)

$\mathrm{EU}=$ Experimental unit

GGE $=$ Genotype main effects plus Genotype $\mathrm{x}$ environmental interaction effect model

$\mathrm{GxE}=$ Genotype $\mathrm{x}$ environmental interaction

$\mathrm{H}_{0}=$ Null hypothesis

LC $=$ Location

Max $=$ Maximum

MCMC $=$ Markov Chain Monte Carlo

Min $=$ Minimum

$\mathrm{MS}=$ Mean square

$\mathrm{RGxE}=\mathrm{R}$ program for the analysis of genotype stability and location value

$\mathrm{RP}=$ Replication

RPid = Replication id, which is an experimental unit

$\mathrm{Sd}=$ Standard deviation

SS $=$ Sum of square

Var $=$ Variance

$\mathrm{YR}=$ Year

$b_{i}=$ Regression slope

$S_{d}^{2}=$ Deviation from regression

$\sigma_{i}^{2}=$ Shukla's variance

$W_{i}=$ Wricke'secovalence

$Y S_{i}=$ Kang's yield stability 
Submit or recommend next manuscript to SCIRP and we will provide best service for you:

Accepting pre-submission inquiries through Email, Facebook, LinkedIn, Twitter, etc. A wide selection of journals (inclusive of 9 subjects, more than 200 journals)

Providing 24-hour high-quality service

User-friendly online submission system

Fair and swift peer-review system

Efficient typesetting and proofreading procedure

Display of the result of downloads and visits, as well as the number of cited articles Maximum dissemination of your research work

Submit your manuscript at: http://papersubmission.scirp.org/

Or contact ajps@scirp.org 